\section{Holding back the tide}

\section{With the Ganges-Brahmaputra delta sinking, the race is on to protect millions of people from future flooding.}

BY QUIRIN SCHIERMEIER

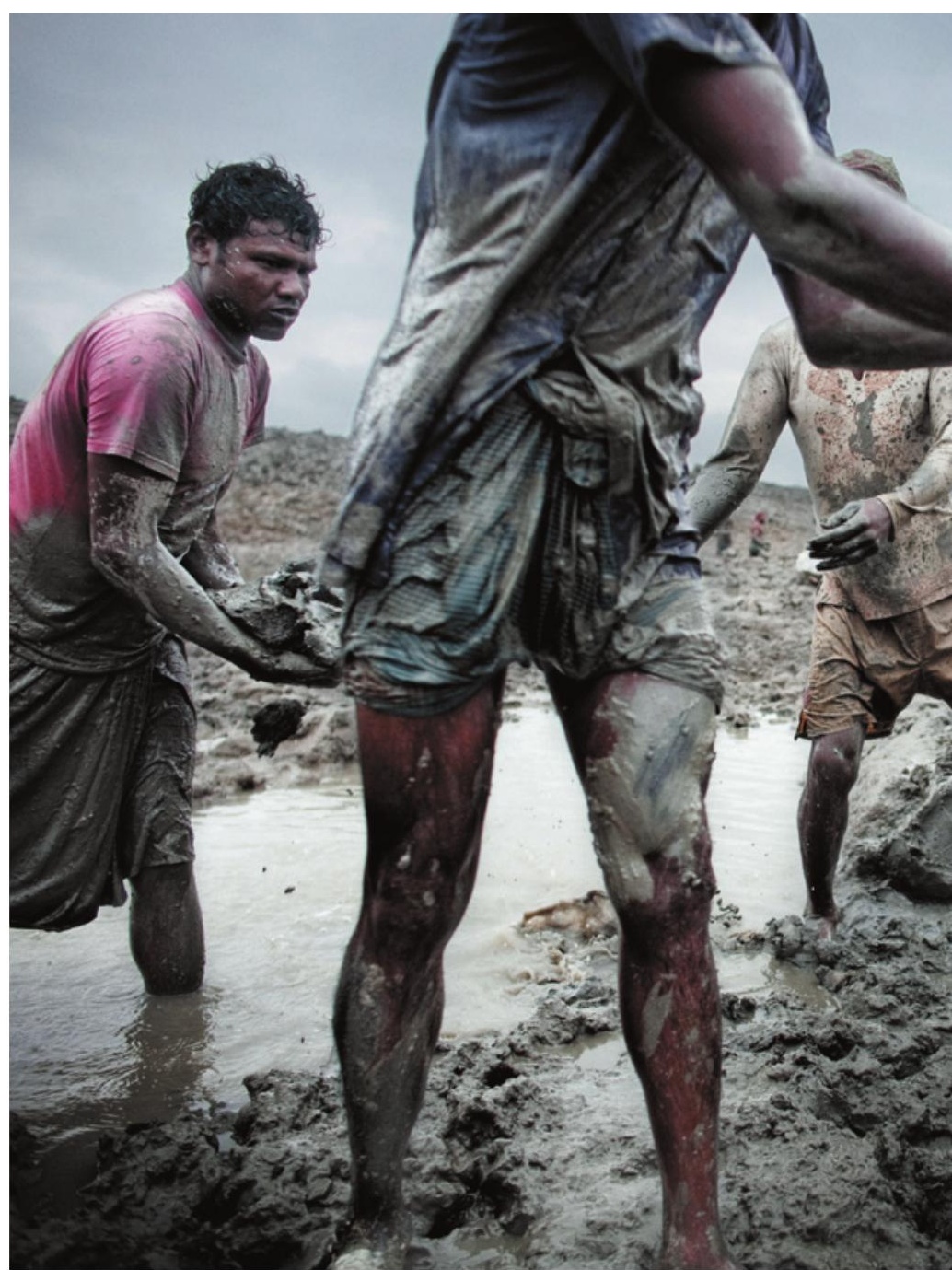

Risks are expected to climb. Global warming is raising sea levels around the planet by $2-3$ millimetres each year. That only adds to bigger problems in the Ganges-Brahmaputra delta, which is sinking so rapidly that the local, relative sea level may be rising by up to 2 centimetres each year. And Bangladesh's population of more than 150 million people is projected to grow by a further 50 million by 2050 , putting more people in harm's way.

Gloomy forecasts warn that millions of Bangladeshis might be displaced by the end of the century. Yet scientists such as Goodbred see a ray of hope. Last month, the country joined with the Netherlands to launch the Bangladesh Delta Plan, to protect the area's people from flooding. To shore up the specifics, researchers are now scrambling to provide basic data on just how fast the delta is sinking and why, and how best to guard against or even stop it.

\section{GOING UNDER}

The Ganges-Brahmaputra delta is the dumping ground of the Himalayas. As wind and rain erode the mountain range, massive rivers carry more than a billion tonnes of sediment into the Bay of Bengal each year; in some places, the layer deposited since the most recent ice age is more than one kilometre thick. As in all deltas, this loose material compacts easily, causing the land to sink slowly and the relative sea level to rise. In the past, sediment carried downstream each year would have refreshed the delta. But agriculture, industry and hydroelectric dams have diverted water and choked the flow of sediments, so the land is no longer being rebuilt. A 2009 study found $^{1}$ that 


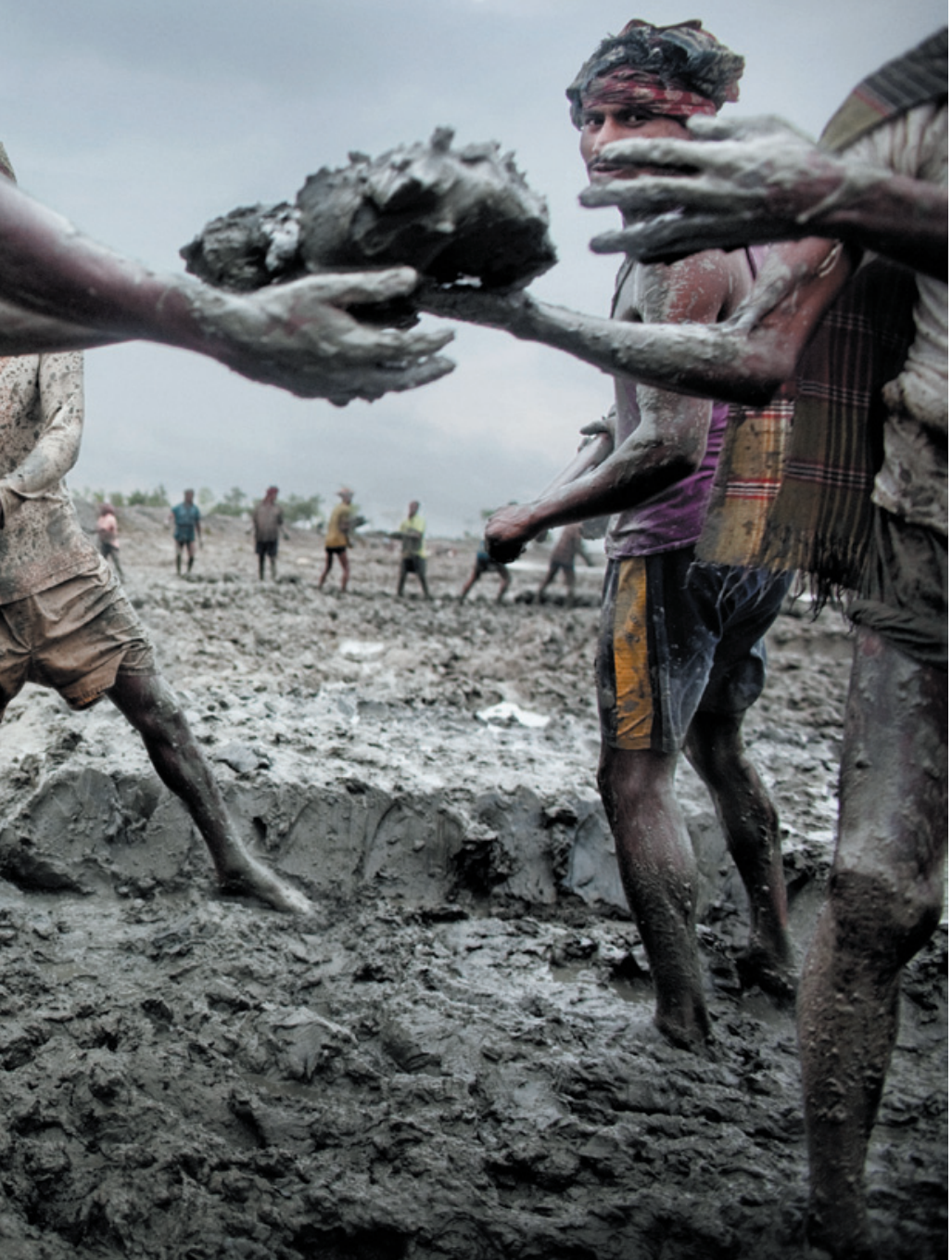

Bangladeshis attempt to rebuild a flood barrier destroyed by Cyclone Aila in 2009.

$85 \%$ of the world's largest deltas suffered severe flooding in the first decade of the twenty-first century. Under current projected rates of sediment sinking and sealevel rise, the area of land at risk on deltas globally is expected to increase by at least half by 2100 .

Previous efforts at flood defence in Bangladesh have not solved the problems. In 1990, the first flood action plan called for barriers to be built along main rivers: in less than 10 years, some 3,500 kilometres of embankments sprang up. In 2000, the country's focus shifted towards constructing more storm shelters and improving warning systems but even so, about three-quarters of Bangladesh's population remains exposed to severe flooding.

A big part of the problem is a lack of understanding of how the delta's behaviour differs from one place to another. Embankments might work to some extent to protect the capital, Dhaka; but as Polder 32 demonstrates, they do not always do their job elsewhere. "Everyone who says something simple about a big delta has never been to one," says James Syvitski, a geologist at the University of Colorado Boulder. For subsidence rates in Bangladesh, he says, "depending on how and where you measure, you might get 15 different values".

Things are dramatically different between the west and east sides of the delta, for example. Over the past several centuries, geological forces and erosion have shifted the lower stretch of the Ganges steadily to the east, leaving the western parts of the delta especially starved of sediment. That makes the southwest particularly vulnerable to both

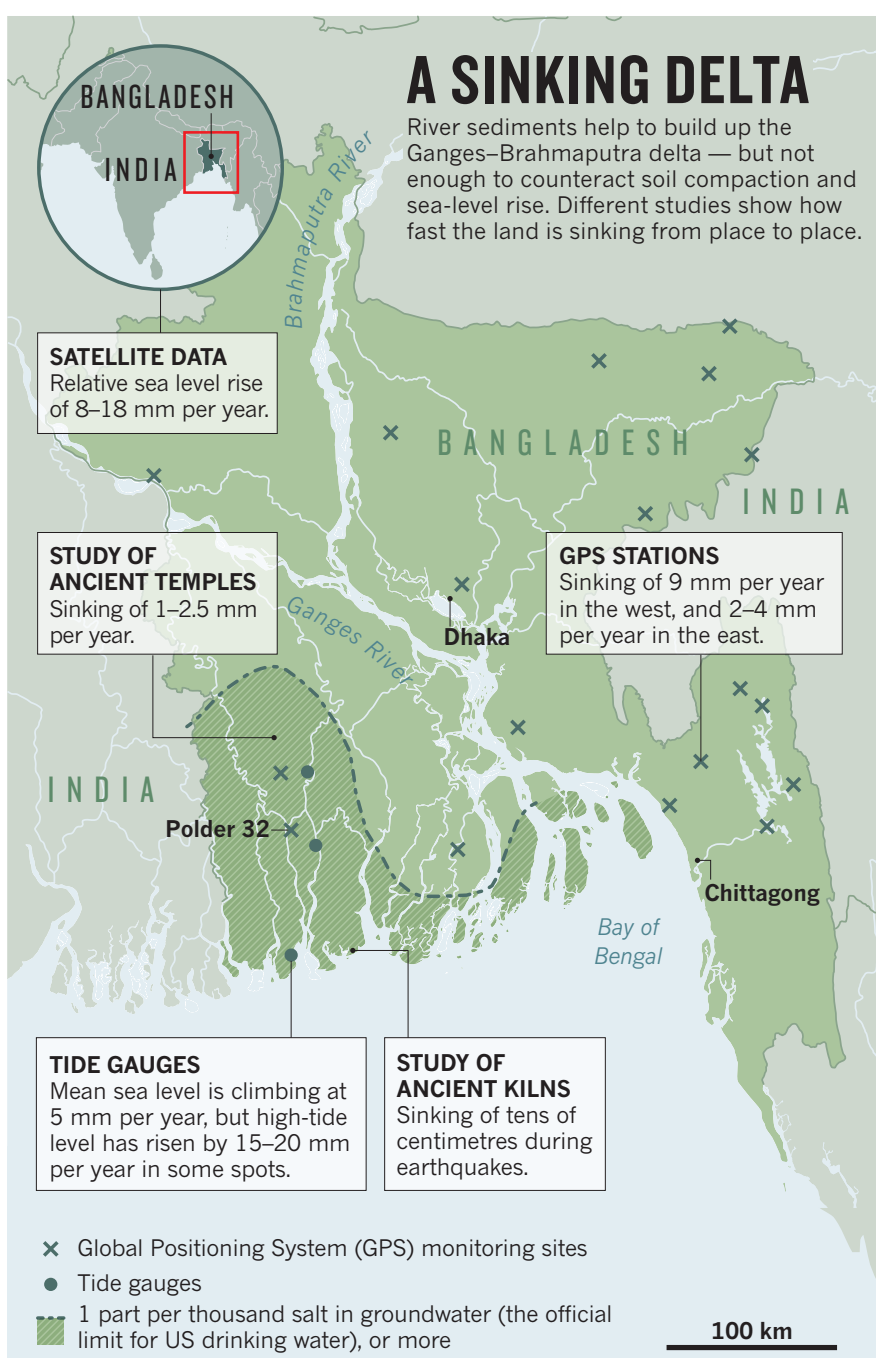

seawater flooding and intrusion of salt into groundwater, which can make the water unfit to drink (see 'A sinking delta'). Researchers need to quantify and map that complexity if policy-makers are to stand a chance of addressing the problems, says Catharien Terwisscha van Scheltinga, a water-management researcher at Wageningen University in the Netherlands who is helping to prepare the Bangladesh Delta Plan.

Syvitski's work with satellite data ${ }^{1}$ suggests that the delta is sinking below sea level by between 8 and 18 millimetres per year. But those numbers need to be checked against ground-based measurements which are now on the way. Michael Steckler, a geologist at Columbia University's Lamont-Doherty Earth Observatory in Palisades, New York, has been installing a network of Global Positioning System (GPS) receivers to monitor subsidence since 2003 . He currently maintains around 20 sites, including one established on Polder 32 last year. So far, the results suggest subsidence rates of some 9 millimetres per year in the southwest, and just 2-4 in the southeast. But the sites are still few and far between, and there are not many in the most vulnerable locations.

Some flood-control efforts might exacerbate the problems. UK geographers John Pethick at Newcastle University and Julian Orford at Queen's University Belfast reported ${ }^{2}$ last year that water levels at some spots in the most vulnerable southwest are much higher than expected. They concluded that embankments along hundreds of tidal channels, some of which reach hundreds of kilometres inland, have vastly reduced the area of land covered by water at high tide. Because the water is less able to spread out, it shoots farther inland where it can. The result is a huge increase in tidal range in less-protected areas. Tide-gauge records 
from three locations in the southwest suggest a mean rate of relative sea-level rise of about 5 millimetres per year over the past 30 years, but some local spots have experienced an average annual high-water-level increase of 15-20 millimetres.

That tidal amplification has big implications for coastal protection, says Goodbred: for areas with long tidal channels, building more embankments could actually cause higher tides and exacerbate saltwater intrusion. But others warn that it is hard to say whether Pethick and Orford's findings will hold true across the southwestern coast - it might depend strongly on the steepness of the channel walls, for example. Extrapolating is "misleading", says Maminul Haque Sarker, a geologist and deputy executive director of the Center for Environmental and Geographic Information Services in Dhaka.

Sarker points to parts of the delta that seem to be sinking much slower. In 2012, he and his colleagues took measurements to see how far the bases of ancient mosques and temples have been buried beneath incoming sediments. The present plinth levels suggest a subsidence rate of just 1-2.5 millimetres per year. Sea-level rise would have to be added to that to get a relative sea-level change. But Sarker thinks that the entire delta is sinking less significantly than researchers such as Syvitski have proposed.

\section{EARTH-SHAKING CHANGE}

Whatever the current rate of subsidence, it may not reflect the full scale of the problem. In 2010, Till Hanebuth, a geolo-

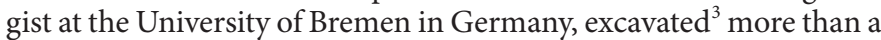
dozen ancient kilns in the Sundarbans, a coastal region of mangrove forests renowned for its population of royal Bengal tigers. The kilns were built for salt production some 300 years ago, just above the winter high-tide level of the time. Today they are buried 1.5 metres beneath the mud and the modern sea level, indicating an average sinking rate of about 5 millimetres per year.

Hanebuth thinks that the drop happened not at a slow, constant pace, but in a succession of abrupt events related to big earthquakes or cyclones. Mud-filled stumps in the area show that mangrove trees died from flooding around 1676 and 1762, when strong earthquakes hit the region. The quake in 1762 , estimated at magnitude 8.8 , caused land around the southeastern city of Chittagong to sink by several metres; in the Sundarbans it seems to have caused at least a 20-centimetre drop, says Hanebuth. Seismologists think that another major quake is overdue in the tectonically unstable region, and that when it comes it will devastate poorly built high-density cities such as Dhaka and Chittagong. It could also cause patches of the delta to drop more in one fell swoop than they have over decades of slow sea-level rise and sediment compaction.

Other complicating factors are easier to assess and guard against. A year after their initial observations, Goodbred and his team returned to Polder 32 armed with GPS receivers and survey tools. They found that the embankments that protect the land from the river and sea had also robbed it of fresh supplies of sediment: during the five decades of its existence, the polder had sunk by a full metre relative to the land outside the embankments because it was not being replenished. On top of that, Goodbred found, local shrimp farmers had drilled holes into the dikes to pipe salt water from coastal rivers into their hatcheries, weakening the barriers.

Although Cyclone Aila brought much suffering to the people, it helped to rescue the land a little. During the two years in which the dikes were broken, the polder rebounded with tens of centimetres of sediment deposited by daily tides. The mud caused havoc in the short term by flooding peoples' floors and gardens, but offers the possibility of long-term sustainability for delta ground.

All this information will feed into the Delta Plan, which will be written over the next 2.5 years by a Dutch-Bangladeshi consortium of government departments, research organizations and engineering consultants. The Netherlands has pledged an initial $€ 7$ million (US\$9.7 million) to develop the strategy. "Having the Netherlands and their invaluable treasure of experience on board is a big push for our flood-defence efforts," says Shamsul Alam, head of the general economics division of Bangladesh's planning ministry, which coordinates the Delta Plan.

The uncertainty in the science makes it difficult for policymakers to see how much investment is justified, and what kind, says van Scheltinga. But at least some of the problem is coming into better focus. "We're only beginning to understand how the delta works - but we know enough to do a bit better," says Goodbred.

In rural coastal areas, Goodbred adds, one solution might be to return to the kind of low, flexible embankments that people in this region built before the 1960s. Locals could raise them in the dry season to keep salty water away, and cut them down in the wet season to allow sediment in. Hugh Brammer, a UK geographer who consulted on Bangladesh's 1990 flood action plan for the World Bank, agrees that flexible barriers are needed. Tidal water must, from time to time, be allowed to flush embanked land, he says, to deposit sediment and thus prevent the polders from sinking over the long term. Homes in these polders, he notes, tend to be on land that sits half a metre or more above the polder basins, so would be protected from the influx.

The most urgent step, says Brammer, is to divert water from the Ganges to the western parts of the delta, so that the people there have access to fresh water in the dry season. In 2008, the Bangladesh government promised to consider one diversion scheme. But the costs and feasibility of such a major engineering project have yet to be properly examined; Alam says that such a diversion is unlikely to happen any time soon.

There are cheaper options, he says. Scientists with the Bangladesh Rice Research Institute in Gazipur have developed salt-tolerant rice to grow in flood-prone plains. In large coastal cities, new homes and public infrastructure could be built on artificially raised land. Near the coast, conserving and planting trees could create a buffer against storm surges.

In its 2011-15 economic plan, Bangladesh earmarked more than 120 billion taka (US $\$ 1.5$ billion) - 4\% of all public expenditure - for climate adaptation and disaster management. Furthermore, it is currently channelling a \$170-million multi-donor climate-change-resilience fund, set up in 2010, into projects including flood protection. More money could come from the multi-billion-dollar international Green Climate Fund. To enact a fully fledged Delta Plan, says Saleemul Huq, a senior fellow in the climate-change group at the International Institute for Environment and Development in London, will require several billion dollars over the next few years. Bangladesh currently gets about $\$ 2$ billion per year from donors for everything from economic development to food relief, so Alam says that it is not unreasonable to hope that it will be able to redirect funds to achieve the flood goals.

Meanwhile, life on Polder 32 is slowly returning to normal. Not all of the destroyed embankments have been repaired or replaced, but hundreds of homesteads and businesses are being moved to higher land both inside and outside the polder. Goodbred trusts that the delta and its people have a future. "Bangladesh is blessed by options," he says. "But time is short and the issues are substantial."

Quirin Schiermeier is a senior reporter for Nature in Munich, Germany.

1. Syvitski, J. et al. Nature Geosci. 2, 681-686 (2009)

2. Pethick, J. \& Orford, J. D. Glob. Planet. Change 111, 237-245 (2013).

3. Hanebuth, T. J. J., Kudrass, H. R., Linstädter, J., Islam, B. \& Zander, A. M. Geology 41, 987-990 (2013). 